\title{
The Positive Side of Eliciting Negative Emotions: Survey Results of Visitor Responses to a Library Exhibit
}

\begin{abstract}
Eliciting emotions, particularly uncomfortable emotions, through exhibition design can have a positive impact on the patrons' reception of the exhibition. In this study, patrons visiting an exhibition designed to create a dark and macabre atmosphere were given an exit survey asking them to identify and rate the intensity of the emotions they felt during the experience. The survey also assessed visitor likelihood of returning to view the exhibition again. In general, visitors who recorded feeling negative emotions while viewing the exhibition were significantly more likely to visit multiple times than those who did not.
\end{abstract}

Curated exhibitions provide opportunities for libraries to entice patrons to come inside, showcase their important collections, and encourage engaged learning within the community. ${ }^{1}$ Much has been written on the practicalities of creating library exhibitions. ${ }^{2}$ For example, Swanick, Rankin, and Reinhart outline best practices for increasing user engagement, including: positioning exhibitions near library entrances, exhibiting a narrow range of items that appeal to a wide variety of patrons, choosing items to exhibit that tell an interesting story, and integrating the use of technology. ${ }^{3}$ However, little research has explored how patrons' emotional response to the content of a library exhibition impacts how it is received. In contrast, exhibitions developed at museums have been studied more broadly in this area. There is evidence indicating that museum exhibitions that elicit a strong emotional response in visitors increase both revisit intentions and intentions to spread

1. Beth Auten, et al., "Using NLM Exhibits and Events to Engage Library Users and Reach the Community," Medical Reference Services Quarterly 32, no. 3 (2013): 267, https:/ / doi.org/10.1080/02763869.201 3.806861 .

2. Jessica Lacher-Feldman, Exhibits in Archives and Special Collections Libraries (Chicago, IL: Society of American Archivists, 2013); Mary Brown and Rebecca Power, Exhibits in Libraries: A Practical Guide (Jefferson, NC: McFarland and Company, 2005); Martin Kalfatovic, Creating a Winning Online Exhibition: A Guide for Libraries, Archives, and Museums (Chicago, IL: ALA Editions of the American Library Association, 2002), available online at https://www.lib.byu.edu/cgi-bin/remoteauth.pl?url=http:/ / search.ebscohost.com/ login. aspx?direct $=$ true $\& \mathrm{db}=$ nlebk $\& A \mathrm{~N}=86014 \&$ site $=$ ehost-live $\&$ scope $=$ site [accessed 3 January 2019].

3. Sean Swanick, Sharon Rankin, and Melinda Reinhart, "Curating Exhibitions in Academic Libraries: Practical Steps," Practical Academic Librarianship: The International Journal of the SLA Academic Division 5, no. 2 (2015): 8-9, available online at https://journals.tdl.org/pal/index.php/pal/article/ view/7011/6096 [accessed 3 January 2019].

(C) 2019 by Megan Frost, Caitlyn Towne-Anderson, and Kendal Ferguson (CC BY-NC [https:// creativecommons.org/licenses/by-nc/4.0/]). 
positive word of mouth. Padilla-Meléndez and Santos found that eliciting positive emotions, such as excitement and enthusiasm, increased levels of satisfaction and potential for positive word-of-mouth communication in a sample of college students visiting a museum exhibit in Spain. ${ }^{4}$ In contrast, Nawijn and Fricke found that experiencing negative emotions predicted higher revisit intentions and increased potential positive word-of-mouth communication than experiencing positive emotions in a sample of museum visitors in Germany. ${ }^{5}$

Commercially, emotions can have a strong impact on the behavior of consumers. Experiencing a strong emotional response to purchasing a product increases the likelihood of sharing the experience with others. ${ }^{6}$ In fact, both positive and negative emotions have been linked to social sharing and remembering details with different outcomes. ${ }^{7}$ Positive emotions have been shown to have more of an effect on association memory. ${ }^{8}$ In a library setting, this suggests that patrons visiting an exhibition who associate the experience with positive emotions might be more likely to remember and talk to others about their experience than those who had little or no emotional response. Negative emotions, in contrast, have been shown to lead to more focused attention than neutral or positive emotions. ${ }^{9}$ This indicates that patrons visiting an exhibition have the potential to engage more deeply with content that evokes uncomfortable or painful emotions in comparison to material that evokes neutral or positive emotions.

While both positive and negative emotions may lead to revisit intentions and increased social sharing, there are times when eliciting negative emotions may

4. Antonio Padilla-Meléndez and María Jesús Santos, "The Role of Satisfaction in Cultural Activities' Word-of-Mouth. A Case Study in the Picasso Museum of Málaga (Spain)," Tourism \& Management Studies 12 (2016): 150-51, http://dx.doi.org/10.18089/tms.2016.12115.

5. Jeroen Nawijn and Marie-Christin Fricke, "Visitor Emotions and Behavioral Intentions: The Case of Concentration Camp Memorial Neuengamme," International Journal of Tourism Research 17, no. 3 (2015): 226, https://doi.org/10.1002/jtr.1977.

6. Christian Derbaix and Joëlle Vanhamme, "Inducing Word-of-Mouth by Eliciting Surprise-A Pilot Investigation," Journal of Economic Psychology 24, no. 1 (2003): 109, https: / / doi.org/10.1016/S01674870(02)00157-5; Bernard Rimé, "Emotion Elicits the Social Sharing of Emotion: Theory and Empirical Review," Emotion Review 1, no. 1 (2009): 80-81, https:// doi.org/10.1177/1754073908097189.

7. Derbaix and Vanhamme, "Inducing Word-of-Mouth by Eliciting Surprise," 109-10; Kambiz Hanzaee and Mahmoud Khanzadeh, "Investigation of the Effect of Consumption Emotions on Satisfaction and Word of Mouth Communications," Middle-East Journal of Scientific Research 9, no. 5 (2011): 570; Narine S. Yegiyan and Andrew P. Yonelinas, "Encoding Details: Positive Emotion Leads to Memory Broadening," Cognition \& Emotion 25, no. 7 (2011): 1259-60, available online at https: / pdfs.semanticscholar.org/80d5/29e5a4264315f62e22fbe2e4cd57ed14e756.pdf [accessed 3 January 2019]; Nawijn and Fricke, "Visitor Emotions and Behavioral Intentions," 221-28; Oliver Luminet, et al., "Social Sharing of Emotion Following Exposure to a Negatively Valenced Situation." Cognition and Emotion 14, no. 5 (2000): 661-88, https: / / doi.org/10.1080/02699930050117666.

8. Christopher Madan, Sarah Scott, and Elizabeth Kensinger, "Positive Emotion Enhances Association-Memory," Emotion (2018): 17-18, https:// doi.org/10.31234/osf.io/jrtcg.

9. Susan Chipchase and Peter Chapman, "Trade-Offs in Visual Attention and the Enhancement of Memory Specificity for Positive and Negative Emotional Stimuli," Quarterly Journal of Experimental Psychology 66, no. 2 (2013): 292, https:/ / doi.org/10.1080/17470218.2012.707664. 
paradoxically be most appealing for patrons. Feeling uncomfortable emotions can actually result in a pleasurable experience that individuals seek out. This can be seen in the popularity of sad or scary movies. The reasons for this apparent paradox have been studied by a number of researchers. ${ }^{10}$ One reason individuals may seek out a movie that evokes intense sadness is because they find pleasure in the emotional state of being "moved"; thus, their overall experience is a positive one. ${ }^{11}$ Further, when individuals feel painful or uncomfortable emotions in response to art, they become more engaged in the work both intellectually and perceptually. ${ }^{12}$ Another reason for seeking out various works of art that evoke uncomfortable emotions is that art gives individuals the ability to experience these painful emotions in a safe environment. ${ }^{13}$ If the work of art becomes overly unpleasant, individuals have the power to disengage from the experience. Finally, the ability to endure painful emotions can provide a feeling of satisfaction that results from an awareness of an individual's own capacity. ${ }^{14}$

The purpose of this study was to explore the relationship between the intensity of participants' self-reported emotions and their self-reported likelihood of returning to view a library exhibition. We analyzed participants' emotional responses to a library exhibition about medicine during the Renaissance period that was specifically designed to be dark and morbid. The exhibit displayed medical books, images, and objects from the 16th and 17th centuries and included written material about topics such as bloodletting, wounds, diseases, and death. In addition to the relationship between self-reported emotion and visitor experience, we explored the relationship between negative and positive emotional intensity and their combined impact on viewers' reception of the exhibit.

\section{Methods}

\section{Participants}

Participants ( $\mathrm{n}=104)$ included university students, staff, faculty, and community members who visited an exhibition at a university library. Demographic information was not collected as part of the survey.

\section{Procedures}

All library patrons who visited the exhibition during three two-hour time periods

\footnotetext{
10. Julian Hanich, et al., "Why We Like to Watch Sad Films: The Pleasure of Being Moved in Aesthetic Experiences," Psychology of Aesthetics, Creativity, and the Arts 8, no. 2 (2014): 130-43, https:// doi.org/10.1037/a0035690; Aaron Smuts, "Art and Negative Affect," Philosophy Compass 4, no. 1 (2009): 39-55, http:// dx.doi.org/10.1111/j.1747-9991.2008.00199.x; Winfried Menninghaus, et al., "The Distancing-embracing Model of the Enjoyment of Negative Emotions in Art Reception," Behavioral and Brain Sciences 40 (2017): 1-63.

11. Hanich, et al., "Why We Like to Watch Sad Films," 139.

12. Smuts, "Art and Negative Affect," 53.

13. Menninghaus, et al., "The Distancing-embracing Model of the Enjoyment of Negative Emotions in Art Reception," 6.

14. Smuts, "Art and Negative Affect," 40, 53.
} 
were invited to take an exit survey. The survey was located on a table outside the exhibit. An administrator at the table asked each exiting patron if he or she would be willing to fill out the five-question survey. Participants were instructed to place the completed questionnaires into a slotted box to ensure anonymity.

\section{Materials}

The Geneva Emotions Wheel (GEW) was used to measure the intensity of participants' self-reported emotions. ${ }^{15}$ The GEW is a tool that assists individuals in identifying and rating the intensity of their emotions. The survey asked respondents to circle the emotions that they experienced while viewing the exhibition and then rate the level of their emotional intensity for each emotion on a five-point Likert scale. Higher scores represented a greater intensity of emotion. Positive emotions on the scale included: interest, amusement, pride, joy, pleasure, contentment, love, admiration, relief, and compassion. Negative emotions on the scale included: anger, hate, contempt, disgust, fear, disappointment, regret, shame, guilt, and sadness.

Participants were also asked if this was the first time they had visited the exhibition and if they planned to return. A question asking participants if they were likely to share their experience with someone else was also included in the survey. This question was originally intended to be included in the statistical analysis; however, the percentage of participants who answered "no" was too small to provide statistically significant results. Both the GEW and the survey questions can be found in appendix A.

\section{Results}

As seen in figure 1, six emotions were chosen by at least one third of the responders. The most frequent positive emotion was interest, which almost all participants reported experiencing. This was followed by amusement, admiration, and compassion. The two most frequent negative emotions were disgust and sadness.

\section{Data Analyses}

Individual survey results were initially checked for irregularities. Notably, four of the survey respondents rated all 20 emotions, and a fifth respondent rated 19 of the 20 emotions. In contrast, the next highest number of ratings was only 12 , and the median respondent rated only 4 emotions. We believe that these five high respondents may have been treating " 1 " as their baseline, instead of the " 0 " baseline that everyone else used. For our statistical analysis, we therefore adjusted their ratings as follows: $1=0,2=1.25,3=2.5,4=3.75$, and $5=5$. We then rounded these values to the nearest integer to produce the plots displayed in our plots.

15. Klaus R. Scherer, et al., "The GRID Meets the Wheel: Assessing Emotional Feeling via Selfreport" (2013): 1-63, https:// doi.org/10.1093/acprof:oso/9780199592746.003.0019. 


\section{FIGURE 1}

The length of each line represents the proportion of respondents that rated the corresponding emotion with a 1 or greater

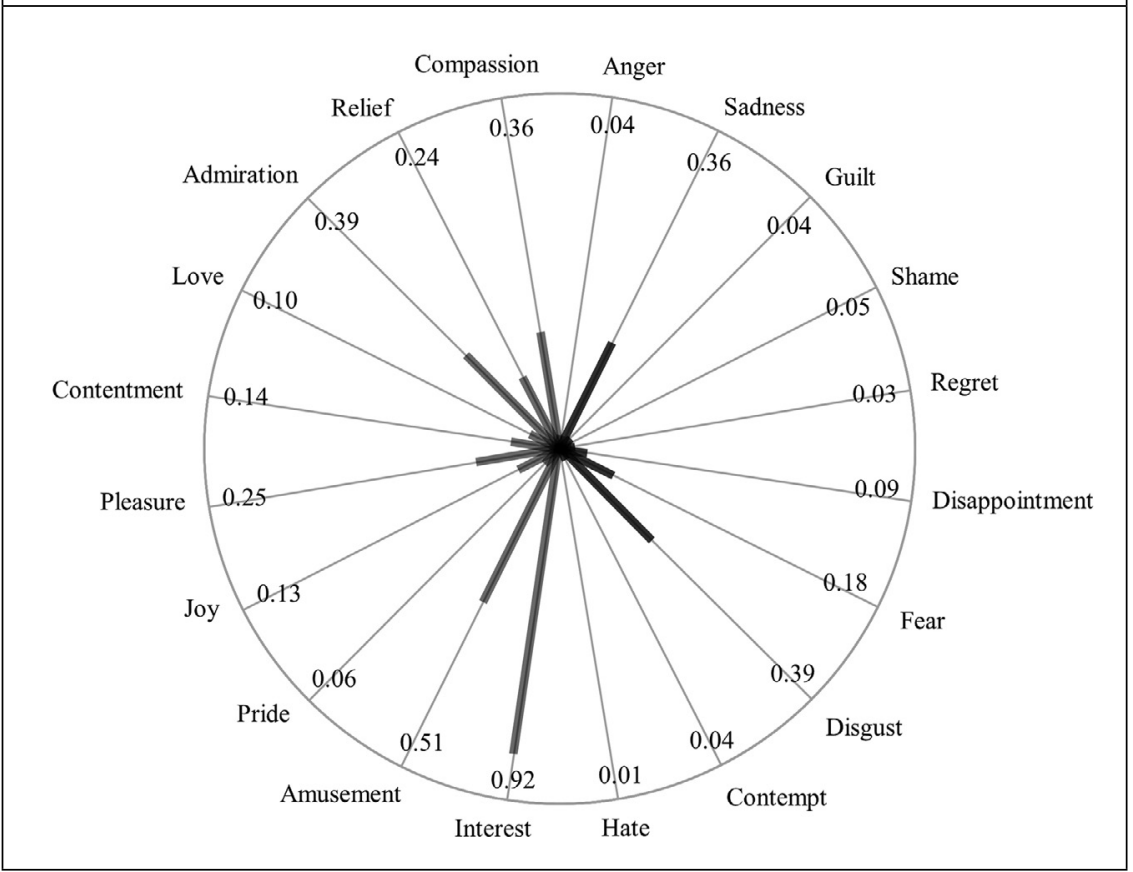

Survey responses were used to produce both positive and negative measures of emotional intensity. The four primary measures included the maximum positive and negative scores (with possible values ranging from 0 to 5 ), and the respective sums of the positive and negative scores (with possible values ranging from 0 to 50). Additional measures included all possible two-way interactions between the positive and negative primary measures and a quadratic term for each primary measure (with possible values ranging from 0 to 25 for the maximum score and from 0 to 2,500 for the sums of scores). In total, twelve such measures were accepted as candidate independent variables for a statistical model.

Using logistic regression, the probability of returning to the exhibit was modeled as a function of a subset of the measures of emotional intensity. To produce a parsimonious model, a backward selection procedure was used to eliminate measures with minimal predictive power. The procedure resulted in a model with only three variables - the sum of the positive scores, the maximum negative score, and the squared maximum negative score.

Table 1 displays the coefficients for the included measures and their statistical significance. As shown, each of the negative emotional measures is significant at 
the significance level of $p<.05$. A joint test of significance results in a $p$-value of 0.0034 for the effect of negative emotion. In contrast, the positive measure is only marginally significant, with a $p$-value of 0.0584 . The $p$-value associated with the entire model is 0.0031 . The predictions based on these coefficients are shown in table 2 .

\section{TABLE 1 \\ Summary of Model Fit}

The first column of $p$-values indicates the significance of all model terms. $P$-values for the negative measures are both significant at the 5-percent level, whereas the positive measure is significant at the 10-percent level. The second and third $p$-value columns display the results of a test of joint significance for the two negative measures and for all three explanatory measures, respectively. In both cases, the effects are significant at the 5-percent level.

\begin{tabular}{|l|l|l|l|l|}
\hline Model Coefficient & $\begin{array}{l}\text { Point } \\
\text { Estimate }\end{array}$ & \multicolumn{2}{|l|}{ P-value } \\
\hline Intercept & -0.9525 & 0.0650 & 0.0650 & 0.0650 \\
\hline Max negative score & 1.3471 & 0.0056 & 0.0034 & 0.0031 \\
\hline Square of max negative score & -0.2438 & 0.0264 & & \\
\hline Sum of positive scores & 0.0708 & 0.0584 & 0.0584 & \\
\hline
\end{tabular}

\section{TABLE 2}

Predicted Probability of Returning Based on Model Point Estimates

\begin{tabular}{|c|c|c|c|c|c|c|}
\hline Max Negative Score & \multicolumn{6}{|l|}{ Sum of Positive Scores } \\
\hline & 5 & 10 & 15 & 20 & 25 & 30 \\
\hline 0 & 0.35 & 0.44 & 0.53 & 0.61 & 0.69 & 0.76 \\
\hline 1 & 0.62 & 0.70 & 0.77 & 0.83 & 0.87 & 0.91 \\
\hline 2 & 0.75 & 0.81 & 0.86 & 0.90 & 0.93 & 0.95 \\
\hline 3 & 0.78 & 0.83 & 0.88 & 0.91 & 0.93 & 0.95 \\
\hline 4 & 0.71 & 0.78 & 0.83 & 0.88 & 0.91 & 0.93 \\
\hline 5 & 0.51 & 0.60 & 0.68 & 0.75 & 0.81 & 0.86 \\
\hline
\end{tabular}


Figure 2 shows the intensity scores. These are the highest levels of emotion that participants rated both their strongest positive and negative emotions. In this graph, the area of the circle is proportional to the number of survey results at each point. Visitors recorded a higher number of positive emotions than negative emotions to describe their experience with the exhibit; however, most responders experienced at least some levels of negative emotion. Only one responder did not record any positive emotion.

The probability of returning is displayed for several combinations of the maximum negative score and the sum of positive scores in figures 3 and 4 . Figure 3 depicts the effect of an increase in the maximum negative score for three scenarios based on predictions for individuals with different sums of positive ratings. These predictions were plotted while maintaining the sum of positive scores at a fixed level. Similarly, figure 4 depicts the effect of an increase in the sum of positive scores for three scenarios based on predictions for individuals with different negative maximum ratings. These predictions were plotted while maintaining the maximum negative score at a fixed level.

\section{FIGURE 2 \\ Correlation between the maximum positive response and the maximum negative response}

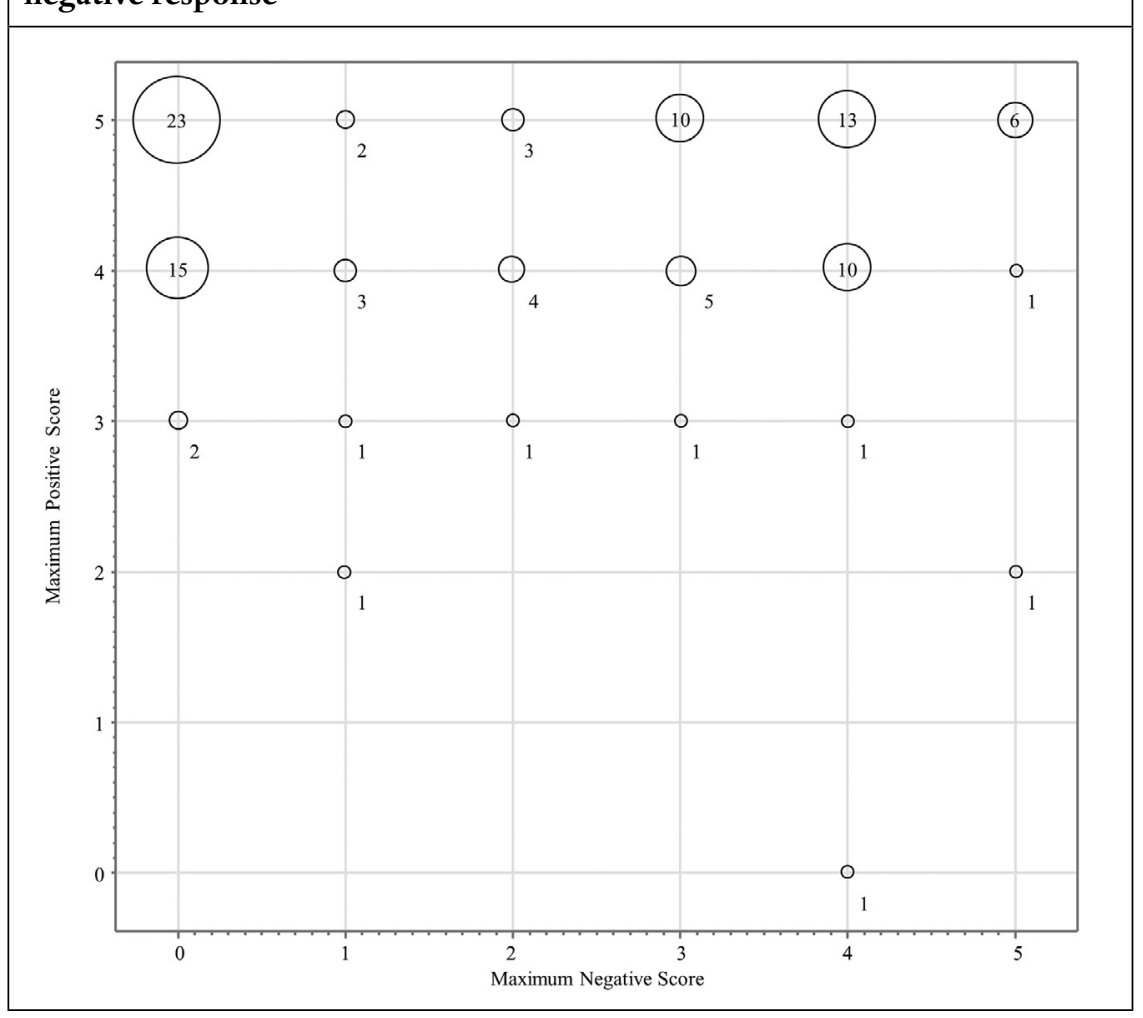




\section{FIGURE 3}

Conditional probability of returning as a function of negative rating

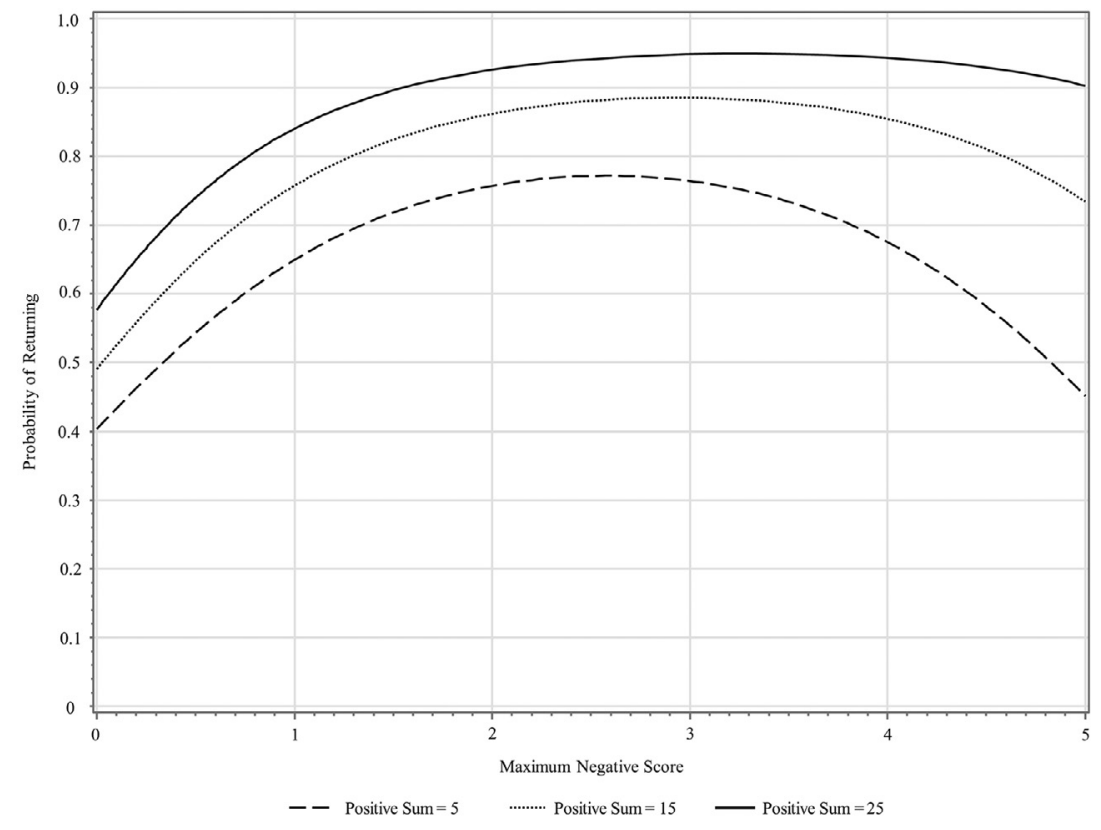

FIGURE 4

Conditional probability of returning as a function of positive rating

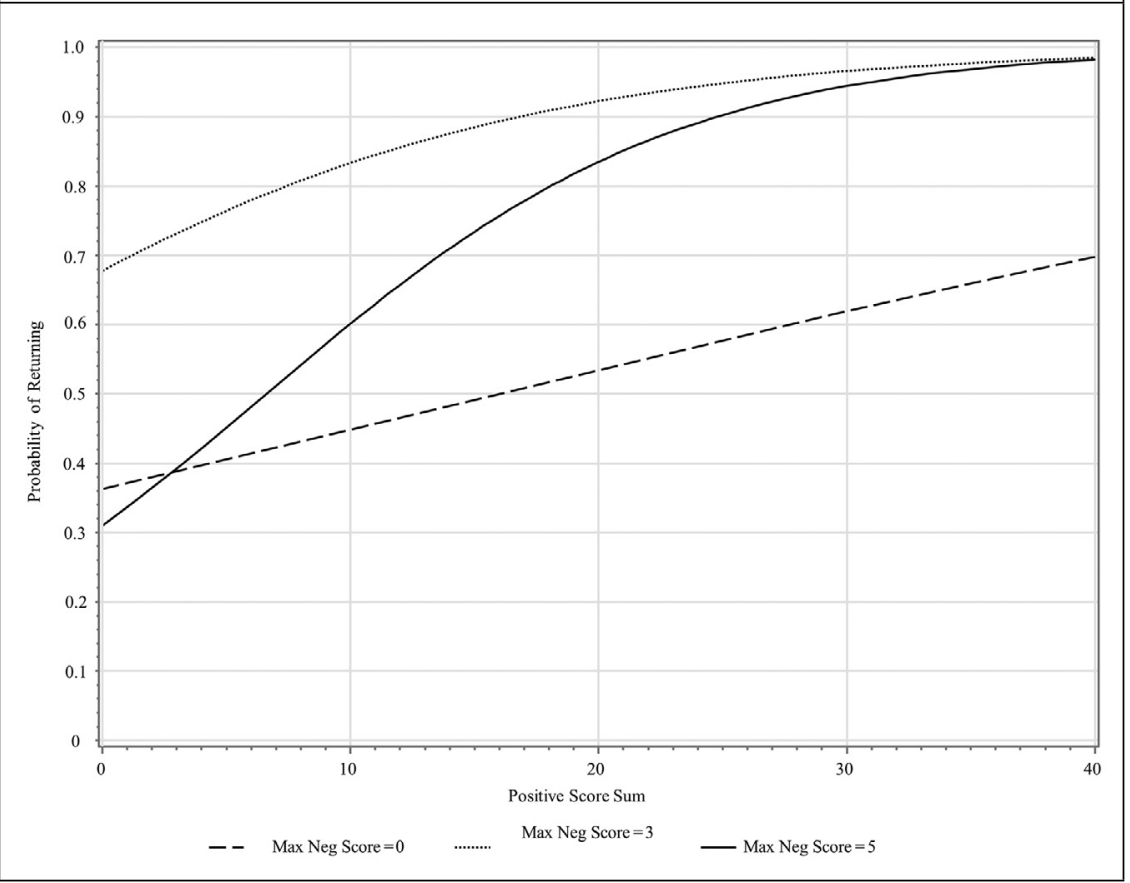




\section{Discussion and Conclusion}

The purpose of this study was to better understand how the quality (positive or negative) and intensity of a viewer's emotional response to an exhibit impacts the likelihood that they will return to view the exhibit again.

Our statistical analysis revealed that negative emotions significantly predicted visitor intention as seen in figure 3 . Those visitors who recorded feeling negative emotions while viewing the exhibit were significantly more likely to report an intention to visit the exhibit again. In general, as the intensity of negative emotions increased, visitor response also increased. At a certain point, however, this correlation reversed. Those who recorded the highest levels of negative emotion became increasingly less likely to return. It is possible that there is a tipping point where negative emotions become unpleasant enough that visitors do not want to return.

We expected that, as the intensity of positive emotional response increased, we would see a corollary increase in the likelihood that a visitor would return to the exhibit. While our results did indeed show this relationship as displayed in figure 4, they were only statistically significant at the 10 percent, and not at the 5 percent, significance level. This low statistical significance seems counterintuitive especially in comparison to the highly significant correlation found with negative emotions. It is possible that, when evaluating positive experiences alone, we were not able to detect the richness that negative emotion added to the visitors' overall experience.

This research may be of benefit to exhibit curators and designers. As in other forms of entertainment that tell a story, such as movies and video games, many individuals enjoy feeling some degree of negative emotion. ${ }^{16}$ Creating exhibits that deliberately elicit not only positive but also negative emotions have the potential to enhance the richness of the experience, boost visitor interest, and increase viewership.

It is important to note that our data was collected from a single exhibition at a single university. It is not intended to shape exhibit policies or practices, and neither the study nor the authors are advocating for negative exhibits. Our intent is rather to inspire further consideration and research on the topic of emotional response to library exhibits.

\section{Limitations and Suggestions for Further Research}

In this study we looked at the intention that visitors had of returning to the exhibit. These intentions may not, however, result in actual behavior. We did not collect

16. Hanich, et al., "Why We Like to Watch Sad Films," 130-43; Smuts, "Art and Negative Affect," 39-55; Menninghaus, et al., "The Distancing-embracing Model of the Enjoyment of Negative Emotions in Art Reception," 1-63. 
the longitudinal data required to determine if individuals who intended to return resulted in higher repeat viewership.

Our results only represent those who wished to participate; it is possible that the demographics of our participants, primarily students at a private university, may not extrapolate to the general public. Additionally, individuals who did not want to experience negative emotions may have avoided the exhibit and may therefore be underrepresented in the data.

Our exhibition and the resulting research represents only one subject and its impact on visitors. The subject of our exhibition is highly relevant to the results of our study, and it should not be extrapolated to all other subjects that illicit negative emotions. To illustrate, the high rates of morbidity during the Renaissance may have left our visitors feeling pleased that they did not live during the 1600 s or thankful for modern medicine. In contrast, an exhibit that inspires negative feelings that may be less resolved or more present in people's lives, such as climate change or child abuse, might have a very different effect. Further research is needed to understand how patrons might respond differently to a variety of subjects.

\section{Bibliography}

Auten, Beth, Hannah F. Norton, Michele R. Tennant, Mary E. Edwards, Nina StoyanRosenzweig, and Matthew Daley. "Using NLM Exhibits and Events to Engage Library Users and Reach the Community." Medical Reference Services Quarterly 32, no. 3 (2013): 266-89. https: / / doi.org/10.1080/02763869.2013.806861.

Brannock, Jennifer. "Creating an Exhibit in Special Collections and Using It to Promote Collections and Educate Users." Mississippi Libraries 73, no. 2 (2009): 32-34. https: / / doi.org/10.1080/01930826.2012.684508.

Brown, Mary, and Rebecca Power. Exhibits in Libraries: A Practical Guide. Jefferson, NC: McFarland and Company, 2005.

Chipchase, Susan Y., and Peter Chapman. "Trade-Offs in Visual Attention and the Enhancement of Memory Specificity for Positive and Negative Emotional Stimuli.” The Quarterly Journal of Experimental Psychology 66, no. 2 (2013): 277-98. https: / / doi.org/10.1080/17470218.2012.707664.

Derbaix, Christian, and Joëlle Vanhamme. "Inducing Word-of-Mouth by Eliciting Surprise-A Pilot Investigation.” Journal of Economic Psychology 24, no. 1 (2003): 99-116. https: / / doi.org/10.1016/S0167-4870(02)00157-5.

Hanich, Julian, Valentin Wagner, Mira Shah, Thomas Jacobsen, and Winfried Menninghaus. "Why We Like to Watch Sad Films. The Pleasure of Being Moved in Aesthetic Experiences." Psychology of Aesthetics, Creativity, and the Arts 8, no. 2 (2014): 130-43. https: / / doi.org/10.1037/a0035690.

Hanzaee, Kambiz Heidarzadeh, and Mahmoud Khanzadeh. "Investigation of the Effect of Consumption Emotions on Satisfaction and Word of Mouth Communications.” Middle-East Journal of Scientific Research 9, no. 5 (2011): 566-71. https:/ / 
pdfs.semanticscholar.org/80d5/29e5a4264315f62e22fbe2e4cd57ed14e756.pdf.

Kalfatovic, Martin. Creating a Winning Online Exhibition: A Guide for Libraries, Archives, and Museums. Chicago, IL: American Library Association, 2002. https:// www.lib.byu.edu/cgi-bin/remoteauth.pl?url=http:/ / search.ebscohost.com/ login. aspx?direct $=$ true $\& \mathrm{db}=$ nlebk $\& A \mathrm{~N}=86014 \&$ site $=$ ehost-live $\&$ scope $=$ site.

Lacher-Feldman, Jessica. Exhibits in Archives and Special Collections Libraries. Chicago, IL: Society of American Archivists, 2013.

Luminet, Olivier, Patrick Bouts, Frédérique Delie, Antony S.R. Manstead, and Bernard Rimé. "Social Sharing of Emotion Following Exposure to a Negatively Valenced Situation." Cognition and Emotion 14, no. 5 (2000): 661-88. https:/ / doi.org/10.1080/02699930050117666.

Madan, Christopher R., Sarah M.E. Scott, and Elizabeth A. Kensinger. "Positive Emotion Enhances Association-Memory.” Emotion (April 2018): 1-8. https:// doi.org/10.1037/emo0000465; 10.1037/emo0000465.supp (Supplemental).

Menninghaus, Winfried, Valentin Wagner, Julian Hanich, Eugen Wassiliwizky, Thomas Jacobsen, and Stefan Koelsch. "The Distancing-Embracing Model of the Enjoyment of Negative Emotions in Art Reception." Behavioral and Brain Sciences 40 (2017): 1-63.

Nawijn, Jeroen, and Marie-Christin Fricke. "Visitor Emotions and Behavioral Intentions: The Case of Concentration Camp Memorial Neuengamme." International Journal of Tourism Research 17, no. 3 (2015): 221-28. https: / doi. org $/ 10.1002 /$ jtr. 1977.

Novara, Elizabeth A., and Vincent J. Novara. "Exhibits as Scholarship: Strategies for Acceptance, Documentation, and Evaluation in Academic Libraries." The American Archivist 80, no. 2 (2017): 355-72. https:// doi.org/10.17723/0360-908180.2.355.

Padilla-Meléndez, Antonio, and María Jesús Santos. "The Role of Satisfaction in Cultural Activities' Word-of-Mouth. A Case Study in the Picasso Museum of Málaga (Spain).” Tourism \& Management Studies 12 (2016): 145-52. http:// dx.doi.org/10.18089/tms.2016.12115.

Paver, Chloe. "Exhibiting Negative Feelings: Writing a History of Emotions in German History Museums.” Museum and Society 14, no. 3 (2016): 397-411. https:// journals.le.ac.uk/ojs1/index.php/mas/article/view/681/ 634 .

Rimé, Bernard. "Emotion Elicits the Social Sharing of Emotion: Theory and Empirical Review.” Emotion Review 1, no. 1 (2009): 60-85. https:/ / doi. org/10.1177/1754073908097189.

Smuts, Aaron. "Art and Negative Affect." Philosophy Compass 4, no. 1 (2009): 39-55. http:/ / dx.doi.org/10.1111/j.1747-9991.2008.00199.x.

Swanick, Sean, Sharon Rankin, and Melinda Reinhart. "Curating Exhibitions in Academic Libraries: Practical Steps.” Practical Academic Librarianship: The International Journal of the SLA Academic Division 5, no. 2 (2015): 1-22. https: / / journals.tdl.org/pal/index.php/pal/article/view/7011/ 6096 .

Um, Seoho, Kaye Chon, and YoungHee Ro. "Antecedents of Revisit Intention." Annals of Tourism Research 33, no. 4 (2006): 1141-58. https:// doi.org/10.1016/j. annals.2006.06.003. 